\title{
The Relationship between Milling Surface Morphology and Corrosion Rate of Nickel Base Superalloy
}

\author{
Jinping Shi ${ }^{a}$, Yang Qiao ${ }^{\mathrm{b}}$ and Peiquan Guo ${ }^{\mathrm{c}}$ \\ School of Mechanical Engineering, University of Jinan, Shandong 250022, China \\ ame_shijp@ujn.edu.cn, ${ }^{\mathrm{a}} \mathrm{me}$ _qiaoy@ujn.edu.cn, ${ }^{\mathrm{c} o s s}$ _guopq@ujn.edu.cn
}

Keywords: superalloy, surface morphology, average rate of corrosion

Abstract. Through the milling of nickel base superalloy, this paper studies the effect regularity of surface morphology on corrosion resistance of nickel base superalloy under the condition of different milling parameters. In order to be more intuitive to characterize the surface morphology, this paper defines Motif area ratio to characterize the surface topography. It is defined as the ratio of the surface area that can meet the threshold condition to the machined surface. Take surface roughness for an example to study the relationship between the surface roughness and the corrosion rate of workpiece. Experiment shows that the workpiece surface topography is the direct reason of the difference of corrosion resistance of workpiece material. The better surface morphology, the lower workpiece average corrosion rate and the worse surface morphology, the rapider average corrosion rate.

\section{Introduction}

FGH97 is a new generation of nickel base superalloy powder in China following the development of FGH95 and FGH96. Compared to the previous two generations of powder metallurgy superalloy, FGH97 has higher creep rupture strength, creep resistance, low crack growth rate and other advantages. FGH97 powder metallurgy superalloy turbine disk has been applied to some engine. It has become the first choice for manufacturing high thrust weight ratio engine [1]. So the research on corrosion resistance of FGH97 is particularly important.

\section{Milling Test}

Nickel base superalloy is difficult to machine, in addition to the material itself unique heat induced pore structure outside [2-4]. Its material composition is show in Table 1. Its physical properties are important reasons for material processing. Strengthening phase $\gamma^{\prime}$ accounts for about $64 \%$ mass fraction of alloy in order to ensure that the alloy has good strengthening effect, the tensile strength of $1510 \mathrm{MPa}$, yield strength of $1080 \mathrm{MPa}$, material density of $8.36 \mathrm{~g} / \mathrm{cm}^{3}$ [5]. The solid solution temperature can reach 1180-1190 degrees centigrade.

Table 1 Chemical composition of FGH97 (wt\%)

\begin{tabular}{cclllll}
\hline $\mathrm{C}$ & $\mathrm{Cr}$ & $\mathrm{Co}$ & $\mathrm{Al}$ & $\mathrm{Ti}$ & $\mathrm{W}$ & $\mathrm{Mo}$ \\
\hline 0.04 & 9.0 & 15.5 & 4.9 & 1.8 & 5.5 & 4.0 \\
\hline $\mathrm{Nb}$ & $\mathrm{Hf}$ & $\mathrm{B}$ & $\mathrm{Zr}$ & $\mathrm{Mg}$ & $\mathrm{Ce}$ & $\mathrm{Ni}$ \\
\hline 2.6 & 0.3 & $\leq 0.015$ & $\leq 0.015$ & $\leq 0.02$ & $\leq 0.01$ & bal \\
\hline
\end{tabular}

In order to facilitate the analysis of experimental parameters on the experimental results, this experiment using single factor experiment method to inspect the influence of cutting velocity, per tooth feed, axial depth of cut, radial depth of cut on the test results. Among them, the radial cutting depth remained unchanged, other parameters are shown in table 2. 
Table 2 Cutting conditions

\begin{tabular}{cccc}
\hline $\begin{array}{c}\text { Cutting speed } \\
(\mathrm{m} / \mathrm{min})\end{array}$ & $\begin{array}{c}\text { Feeding rate } \\
(\mathrm{mm} / \mathrm{z})\end{array}$ & $\begin{array}{c}\text { Depth of cut } \\
(\mathrm{mm})\end{array}$ & $\begin{array}{c}\text { Width of cut } \\
(\mathrm{mm})\end{array}$ \\
\hline 30 & 0.05 & 0.10 & \\
50 & 0.10 & 0.15 & 30 \\
70 & 0.15 & 0.20 & \\
90 & 0.20 & 0.25 & \\
\hline
\end{tabular}

\section{Surface Morphology Characterization}

In order to be more intuitive to characterize the surface morphology of different milling parameters and evaluate the degree of corrosion, this paper defines Motif area ratio parameter. It is defined as the ratio of the surface area that can meet the threshold condition to the machined surface. The formula is shown as Eq.1. The selection of threshold need to consider the actual situation that does not affect the subsequent experimental results. As shown in Figure 1, the black area represents the Motif area that meet the threshold condition. In this experiment, the selection of threshold area does not affect the result of surface morphology on corrosion resistance of the workpiece.

$$
P_{S}=\frac{\sum_{i=1}^{n} S_{i}}{S} \times 100 \%
$$

Where $P_{\mathrm{s}}$ is the Motif area ratio, $S_{\mathrm{i}}$ is the surface area that meet the threshold condition, $S$ is the whole surface area.

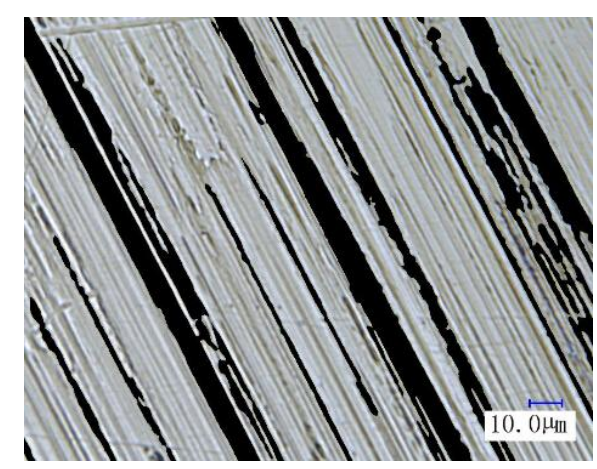

Fig. 1 Motif area meeting threshold condition

The influence of cutting speed on workpiece surface topography. With the increase of cutting speed, the Motif area ratio starts smoothly and then increases rapidly. From Fig.1 and Fig. 2, we can find that the result of Motif area ratio method is close to the amplitude parameter characterization method.

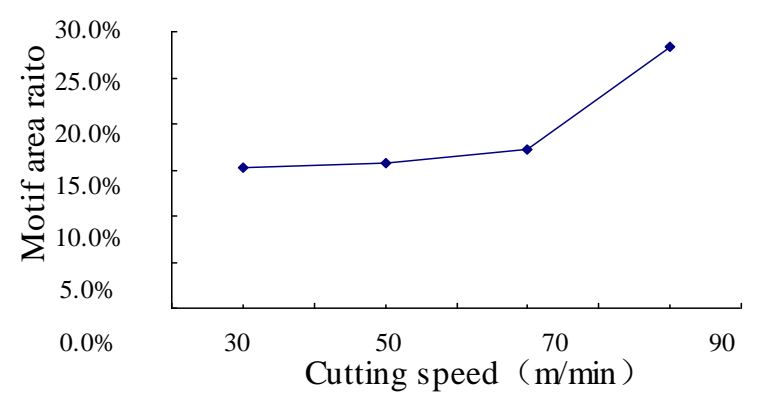

Fig. 2 Relationship between cutting speed and Motif area ratio 
The influence of feed per tooth on workpiece surface topography. With the increase of feed per tooth, Motif area ratio increases gradually. In the process of cutting, with the increase of feed per tooth, cutting force and plastic deformation become larger. Therefore, the scallop height on workpiece increases so as to increases the Motif area ratio shown in Fig. 3.

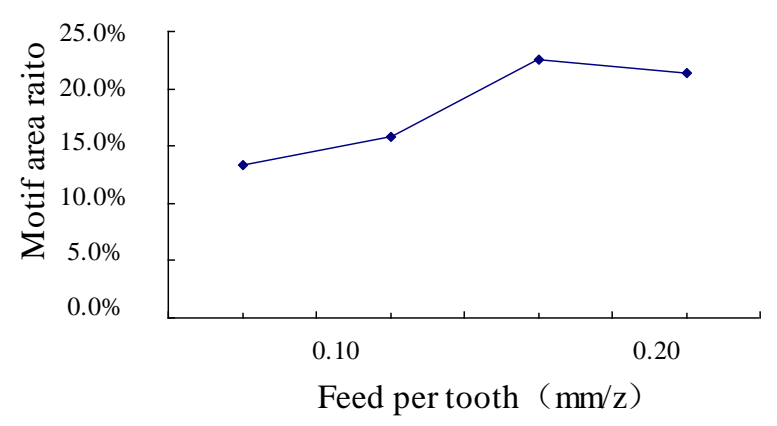

Fig. 3 Relationship between feed per tooth and Motif area ratio

The influence of axial depth of cut on workpiece surface topography. As shown in Fig. 4, the influence of axial depth of cut on surface Motif area ratio is not obvious, but because of the Motif area ratio value itself is at a relatively high position, mean value at around $20 \%$. Therefore, we can conclude that the axial depth of cut has a significant influence on Motif area ratio.

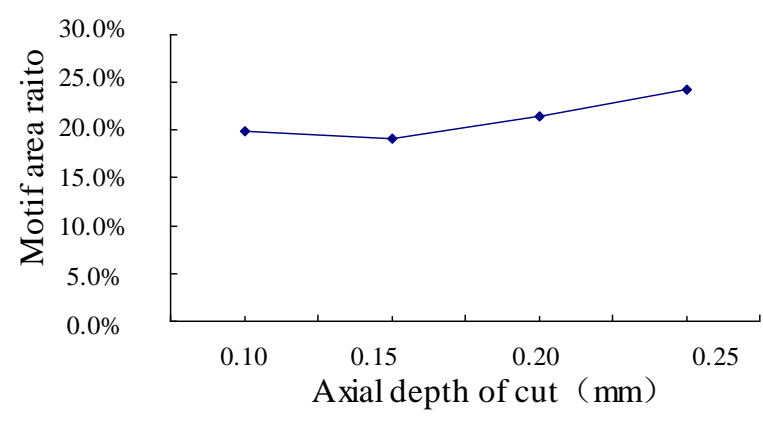

Fig. 4 Relationship between depth of cut and Motif area ratio

\section{Relationship between Surface Topography and Average Corrosion Rate}

This paper makes a test with above workpiece on full immersion corrosion of simulating marine environment. In addition to the machined surface, the remaining five surfaces are painted completely in order to avoid corrode. The test time is $1200 \mathrm{~h}$ and the experimental process reference JB/T 7901-1999"metallic materials laboratory uniform corrosion full immersion test method".

Average corrosion rate is used to evaluate the test results as shown in Ep. 2.

$$
V_{\mathrm{a}}=\frac{k W}{A t \rho}
$$

Where $V_{\mathrm{a}}$ is average corrosion rate, $k$ is a constant, $W$ is corrosion weight loss, $A$ is sample surface area, $t$ is test time, $\rho$ is the density of the material.

The influence of cutting speed on workpiece corrosion. Under the condition of different cutting speed, this paper extracts surface roughness value from the 3D surface topography information and draws the curve of average corrosion rate and surface roughness in Fig.5.

Compared to the average corrosion rate curve and the surface roughness curve can be found that the change tendency of both is basically the same, when the value of the surface roughness increases, the average corrosion rate becomes larger; when the value of surface roughness is small, the average corrosion rate is smaller. That is to say average corrosion rate of workpiece varies with the change of surface roughness. When 
the cutting speed is $90 \mathrm{~m} / \mathrm{min}$, there occurs tool tipping, so in this paper we omit the corrosion result out of

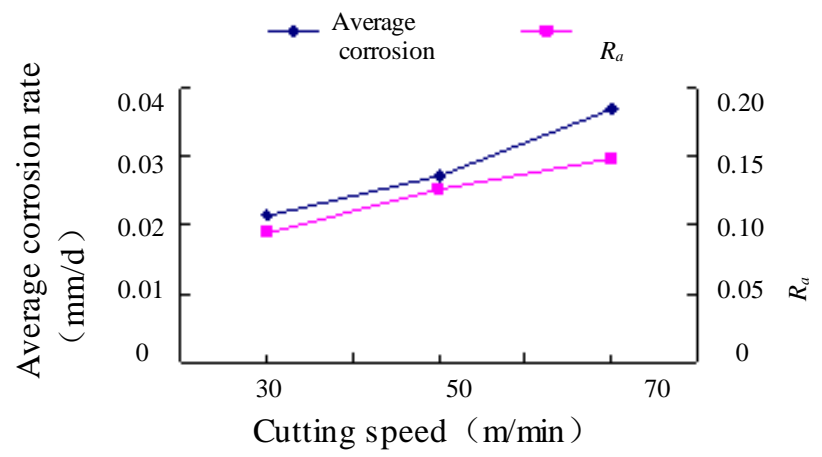

Fig.5.

Fig. 5 Influence of cutting speed on roughness and corrosion

The influence of feed per tooth on workpiece corrosion. Under the condition of different feed per tooth, this paper extracts surface roughness value from 3D surface topography information and draws the curve of average corrosion rate and surface roughness in Fig. 6.

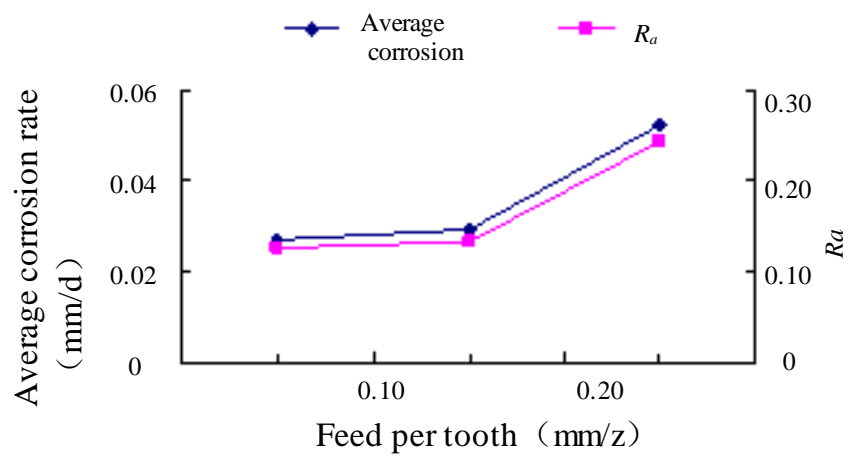

Fig. 6 Influence of feeding rate on roughness and corrosion

The influence of axial depth of cut on workpiece corrosion. Under the condition of different axial depth of cut, this paper extracts surface roughness value from 3D surface topography information and draws the curve of average corrosion rate and surface roughness in Fig. 7.

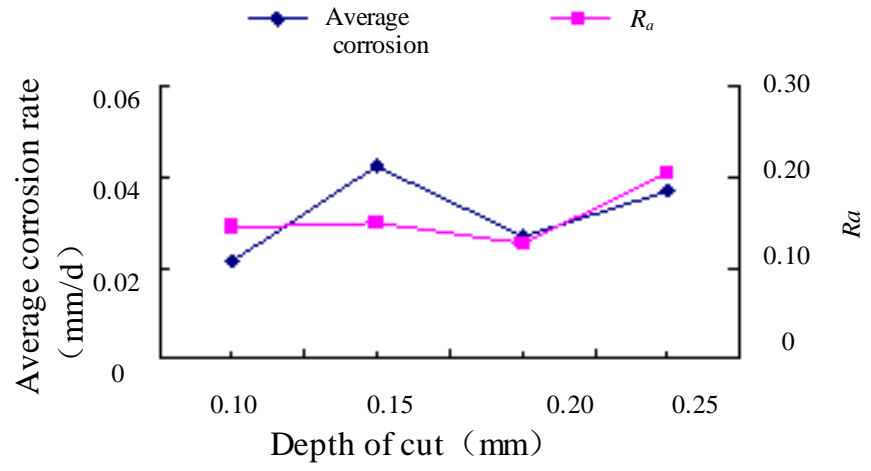

Fig. 7 Influence of depth of cut on roughness and corrosion

From the figure can be found that along with the change of axial cutting depth, change low of average corrosion rate is consistent with the change of surface roughness. 


\section{Conclusion}

(1) In order to be more intuitive to characterize the surface morphology of different milling parameters and evaluate the degree of corrosion, this paper defines Motif area ratio parameter. It is defined as the ratio of the surface area that can meet the threshold condition to the machined surface.

(2) Through the experiment found that average corrosion rate varies with the change of surface roughness. The larger the surface roughness, the faster the average corrosion rate. Conversely the smaller the surface roughness, the slower the average corrosion rate. Based on the theoretical analysis, machined surface topography contains a large amount of information, including the surface roughness. If the workpiece surface topography is poorer, the workpiece surface roughness value is relatively large, therefore, the workpiece surface is easy to store large amounts of corrosive medium, combined with the increased surface defects on the workpiece, all this reasons eventually result in that average corrosion rate increased. Therefore, there is a correlation of average corrosion rate and surface roughness.

\section{References}

[1] Y. W. Zhang, J. T. Liu, Development in Powder Metallurgy Surperalloy, Materials China. 32 (2013) $1-11$.

[2] Ali Riza Motorcu, Abdil Kus, Ismail Durgun, The evaluation of the effects of control factors on surfaceroughness in the drilling of Waspaloy superalloy, Measurement. 58 (2014) 394-408.

[3] D.T.Ardi, Y.G. Li, K.H.K. Chan, L.Blunt, M.R. Bache, The effects of machined topography on fatigue life of a nickel based superalloy, Procedia CIRP. 13 ( 2014 ) 19-24.

[4] Dahu Zhu, XiaomingZhang, HanDing, Tool wear characteristics in machining of nickel-based superalloys, International Journal of Machine Tools \& Manufacture. 64 (2013) 60-77.

[5] M. Peterlechner, H. Rosner, E. Nembach, EELS analysis of the nitrogen content of carbide particles in a commercial $\gamma^{\prime}$ strengthened nickel-base superalloy, Scripta Materialia. 107 (2015) 42-45. 